\title{
REPORT ON EXERCISE EMERGENCY AT FENHAM BARRACKS ON 30th NOVEMBER, 1968 AND 1st DECEMBER, 1968
}

\author{
Colonel W. M. ROSS, F.R.C.S., F.F.R., late R.A.M.C. (T.\&A.V.R.)
}

EXERCISE Emergency was the Northumbrian District Medical Exercise for 1968 and included a number of papers on the general theme of Emergency, being broadly divided into Medical Emergencies and Medical Military Emergencies.

In introducing the exercise Colonel W. M. Ross said that we all recognised an emergency and the necessity for taking correct action during such an occasion to prevent further damage and to render first aid. He had invited the speakers to give advice on situations of their own choice which would be of help to the doctor who was not a specialist in the particular field.

In the first paper, Dr. J. S. Inkster, consultant anaesthetist, talking of " Anaesthetic and Resuscitation Emergencies" said he did not wish to deal at length with the classic anaesthetic emergencies, such as airway obstruction and cardiac arrest, but instead dealt with two special situations. Firstly, he mentioned the problem of providing anaesthesia in an emergency, e.g. to a trapped casualty. In this situation the initial approach should include consideration of resuscitation by intravenous infusion and clearing the airway to allow unimpeded respiration. In dealing with painful situations he advised general analgesia, retaining consciousness, as being safer than anaesthesia, and recommended drugs such as morphine, pethidine, Narphen and alcohol. Another useful approach which he recommended was the use of heavy sedation and local anaesthesia. The second role which he considered was that of the anaesthetist chosen to go, perhaps as the only doctor, on an expedition or similar situation in which the likelihood of having to work under difficult conditions could be foreseen. He advised the doctor concerned to prepare thoroughly before leaving base and, in particular, recommended the use of digital and wrist nerve blocks, with local anaesthesia, intravenous regional anaesthesia, and spinal anaesthesia as methods which would allow the same doctor to operate on the patient as well, but he stressed that there must be some capability of administering general anaesthesia. Finally Dr. Inkster stressed the necessity for all doctors, whatever their speciality and training, to be able to do direct laryngoscopy and tracheal intubation because of the great value of these procedures in any emergency.

Mr. James Ashworth, consultant orthopaedic surgeon, dealt with the roadside aspects of " Road Accident Emergencies". He pointed out that the number of deaths from road accidents remained very constant despite advances in first aid and hospital treatment, and explained that this was due to the fact that whereas previously the majority of deaths had been due to injuries to the limbs, injuries which were now much less commonly fatal, the majority of casualties who died following road accidents now had suffered head injuries. He referred to a number of schemes in various parts of the country in which teams based on hospitals had tried to improve the management of road accident casualties, without success, because of difficulties in ensuring that the doctors and their equipment reached the site of the accident sufficiently quickly; he then described the system in North Yorkshire where a group of general practitioners had organised themselves into an emergency service to attend such accidents. The aspects of the problem which were particularly studied were: 
Ventilation by intubation of the larynx,

maintenance of circulation by the use of intravenous cannulae and the use of fluids including plasma expanders,

immobilisation of fractures with particular reference to inflatable splints and the inflatable mattress for spinal and pelvic injuries, but he also commended the Thomas splint as being valuable in appropriate conditions, and referred to the possibility of circulatory collapse at the time of removal of inflatable splints if it had been necessary to apply them to all four limbs, and

the necessity for rapid, smooth and comfortable transport to hospital. He pointed out the need for large dressings and recommended a gauze pad, at least $20^{\prime \prime} \times 15^{\prime \prime}$, for use on the trunk or round limbs, and with respect to cervical spine injuries, which had become more common, the use of an improvised collar to keep the neck extended; he suggested that this would also help to keep the airway free.

Captain J. M. D. Galloway and Major D. M. Karmody, surgical registrars in a peripheral vascular unit, presented a paper entitled "Arterial Injuries" and stressed the importance of arteriography in the diagnosis and management of such injuries. Three types of arterial lesion were seen:

The closed lesion, usually a contusion, as spasm is very rare,

complete loss of continuity, and

incomplete loss of continuity leading to traumatic aneurysm.

The complications likely to be met here were haemorrhage, thrombosis and embolism, gangrene, infection, and aneurysm; they showed the extent of gangrene likely to be related to the level of injury, referring especially to the fact that the popliteal artery injury often needed a higher amputation than an injury to the iliac artery. By means of a number of slides they demonstrated the methods of arterial repair which they recommended.

Dr. A. R. Horler, consultant physician, in a paper entitled '. Medical Emergencies ", said that the commonest causes of admission as an emergency to a medical ward were ischaemic heart disease, acute infections, cerebro-vascular accidents, gastro-intestinal bleeding, and overdose of drugs. He dealt only with the first two of these groups. Referring to coronary thrombosis he described the symptoms, and method of diagnosis, stressing that as the majority of deaths occurred before forty-eight hours all patients should be admitted to a hospital. He described the diagnosis and management of complications including left ventricular failure, arrhythmias, heart block, and cardiac arrest, and discussed the prognosis, relating the average survival to the degree of functional disability remaining after the acute attack. On the subject of acute infections Dr. Horler described the use of antibiotics, stating that penicillin was still probably the best on the whole, despite its known limitations, particularly with regard to penicillinase-producing staphylococci, and its relatively limited spectrum. He gave his indications for the use of penicillin and other antibiotics in a wide variety of acute infections.

Professor J. N. Walton, in a paper entitled " Neurological Emergencies", dealt with three main problems, those lesions which threaten life, tend to produce paralysis of a limb, or threaten vision.

Of the lesions which threaten life he described intra-cranial bleeding, especially subarachnoid haemorrhage, of which 85 per cent were due to aneurysms, and discussed 
the complications, together with the indications for investigation, such as lumbar puncture and angiography, and for operation. He also described intra-cerebral haemorrhage from which the majority of patients died quickly and others were severely disabled, and the more rare intra-cerebellar haemorrhage with its triad symptoms of headache, vomiting and vertigo. Professor Walton described the source and investigations in the patients with emboli and the indications for anti-coagulant treatment. He then described acute necrotising encephalitis, stressing the necessity to reduce intra-cranial pressure rapidly by the use of surgery and steroids. Dealing with those lesions causing progressive paralysis of limbs, Professor Walton stressed the need for action as soon as weakness is seen to progress and the relatively good prognosis in transverse myelitis and the Guillain Barré syndrome, providing respiratory paralysis did not develop. Those lesions which threatened vision included retrobulbar neuritis, benign intracranial hypertension, characterised by malaise, headache and obscuration of vision on stooping, and cranial arteritis, causing sudden loss of sight in one eye. In the benign intracranial hypertension he stressed the risk to vision if bilateral papilloedema were found, even at a time when the symptoms were relatively limited.

Mr. J. Hankinson, consultant neurosurgeon, speaking on "Neurosurgical Emergencies," stressed the need for close co-operation between neurologists and neurosurgeons. Dealing with head injuries, he emphasised the frequent association with injuries to other parts of the body and the need for control of the airway, especially to avoid anoxia and increased cerebral oedema. He said that apart from bleeding, e.g. extradural haemorrhage, shown by progressive changes in conscious level, it was often better to wait for optimum conditions for operating. He then referred to raised intracranial pressure, stressing the importance of excluding the malignant causes so as to save those patients with benign lesions such as chronic subdural haematoma, and advised the use of dehydrating agents such as triple strength plasma, urea, mannitol and Decadron to allow time for investigations to be completed. Referring to spinal cord injuries, Mr. Hankinson said that the damage to the cord was usually maximal at the time of injury although of course care in transport was still necessary to avoid further damage. Laminectomy was considered seldom to be helpful unless myelography had given a definite indication. Acute central prolapsed disc and acute spinal extradural abscess were mentioned as two indications for urgent spinal operations.

Major Myles Gibson, consultant neurosurgeon, stressed how the mortality and morbidity of spinal and head injuries can be improved by specialist neurosurgical treatment and described the arrangements for this support treatment in the Army. There is in the Reserve Army a pool of neurologists and neurosurgeons, supported by sisters and technicians, which can give specialist opinion or treatment to several units simultaneously at any point in the world. For a single case a team comprising a neurosurgeon from Leeds, an anaesthetist from Leeds or Catterick Military Hospital, and a sister from Catterick Military Hospital, with a small number of instruments, can fly at very short notice to any point in the world. For a larger operation the team was based on forward and rear sections, the establishment and equipment of which are continually under review, with particular reference to anaesthetic agents, antibiotics and drugs. The transportable forward element has equipment weighing $670 \mathrm{lb}$., enough for twelve major operations. Any parent unit to which they are attached is required at the time of arrival to give a theatre and ward space, six hours later, sterilising, X-ray and maintenance facilities and from twenty-four hours onwards, additional drugs, dressings etc. 
Major M. Alltree, consultant radiologist, gave a paper entitled "Emergency Movement of a General Hospital ". He referred to the known difficulties of moving a general hospital and suggested the use of freight liner containers to ease the problem as they are already available in commercial practice. He described the size of containers currently available and how they can be transported on tractors or by cranes, and by rail, sea and air. He gave suggestions for the use of various sizes of container as stores, operating theatre, emergency ward, X-ray or pathology department. In the subsequent discussion it was generally agreed that improvement of the present mobility of a general hospital was desirable but doubts were expressed as to whether the freight liner container concept would be acceptable to the Services.

Colonel G. M. Warrack, in a paper entitled "Emergency Field Ambulance", described the war establishment and training of an airborne field ambulance in 1943. He defined emergency as a surprise and the reaction to it and stressed the training, fitness, and morale of all ranks as being necessary to produce a satisfactory reaction. He described the part played by 181 Air Landing Field Ambulance during the landing at Taranto in which the major field ambulance of the division had been lost. The field ambulance was divided between Tunis and Italy and occupied 100 beds in an Italian naval hospital in addition to establishing a collecting organisation. By examples of emergency situations he demonstrated how fit and adequately trained troops can cope with emergencies.

Major B. G. Kernohan, described his experiences in British Honduras, when in 1961 he was sent at short notice from Jamaica to Belise immediately after Hurricane Hattie had struck the area. By means of a number of photographs which he had taken himself he demonstrated the degree of damage caused by the hurricane, especially to the houses, and water supply which was based on roof top tanks, and the importance of keeping all doors and windows of houses firmly closed throughout the whole period of the storm. Further difficulties had been caused because Belise lies at sea level with a very high level of subsoil water.

Mr. C. G. Hanson, Lecturer in Economics at Newcastle University, gave a paper entitled "Financial Emergencies". He stressed the difficulty of recognising a financial emergency by either external criteria, such as the monthly Balance of Payments figure, international debts and reserves or the exchange rate, or by internal criteria such as monetary control, unemployment figures, or retail prices and wages. He showed, with particular reference to the last year since devaluation, that living standards were rising. Government expenditure was increasing and the bank rate was not very high or fully enforced, and therefore he doubted whether the period could be considered one of financial emergency. His paper was particularly welcomed as throwing light on financial terms commonly mentioned in everyday news items, but he was unable to give any firm advice.

Following each paper there was a lively discussion which had to be curtailed to allow the programme to be maintained but which led to animated discussions during the break periods: In his final summing up Colonel Ross suggested that the exercise gave the lie to the oft repeated statement that lectures were no longer necessary; all knowledge and information being now available from the printed word. 